\title{
Posting Alcohol-Related Content and Texting Under the Influence Among Hispanic College Students
}

\author{
Mariany A. Gainza Perez ${ }^{1} \cdot$ Marcos Lerma $^{1} \cdot$ Joshua Torres $^{1} \cdot$ Theodore V. Cooper $^{1}$ (D)
}

Received: 5 November 2020 / Revised: 17 March 2021 / Accepted: 3 May 2021 / Published online: 28 May 2021

(C) The Author(s), under exclusive licence to Springer Nature Switzerland AG 2021

\begin{abstract}
Social media use and texting among college students often coincide with drinking. The present study investigated the associations between monthly alcohol use, social media habits, sharing alcohol references, and drunk texting among Hispanic college students. Participants $(n=620,71.6 \%$ female; Mage $=21.07$ years, $S D=3.60)$ completed an online survey containing: demographics, drug use frequency, Sharing of Alcohol-Related Content on Social Media Sites Scale (SARC), Texting Under the Influence Scale, Strategic Self Presentation Scale, Bergen Social Media Addiction Scale, and iPhone Screen Time. Bivariate correlations assessed relationships between all variables. Six logistic regressions assessed subscales of the SARC, and a linear regression assessed the Texting Under the Influence Scale. Almost 15\% of participants met criteria for social media addiction, almost $40 \%$ reported ever sharing alcohol posts, and approximately $20 \%$ reported drunk texting at least once per month. Participants with iPhones averaged 16.84 weekly hours on social media (based on "screen time"). Frequently posting references of drinking alone was associated with more time on social media, higher social media addiction, and greater public sharing of alcohol content. Conversely, posting references of drinking at social gatherings was associated with privately sharing alcohol references and increased social media addiction. Drunk texting was related to increased age, greater Instagram use, decreased Facebook use, and privately sharing alcohol posts. Findings suggest patterns of drinking and sharing alcohol-related content to inform health promotion efforts, especially while many during COVID-19 are heightening use of alcohol and social media.
\end{abstract}

Keywords Alcohol-related content $\cdot$ Social media $\cdot$ Texting $\cdot$ Hispanics $\cdot$ College students

Social media is one of the most popular forms of communication among young adults. Almost $95 \%$ of US college students use at least one social networking site (SNS; Hoffman et al., 2017), and they engage on them $46 \mathrm{~h}$ per month (Gutierrez \& Cooper, 2016). Given the habitual use of SNS and the culture of frequent alcohol consumption among college students, there is an emerging interest in drinking, sharing alcohol references on SNS, and drunk texting. This study assessed the relationships that sharing alcohol references on social media and texting under the influence may have with alcohol consumption, social media addiction, self-presentation, and social media habits.

Theodore V. Cooper

tvcooper@utep.edu

1 Prevention and Treatment of Clinical Health Laboratory, Department of Psychology, The University of Texas, El Paso 500 West University Ave, El Paso, TX 79968, USA
According to the self-generated media hypothesis, people's beliefs, attitudes, cognitions, and behaviors can be affected by direct (e.g., creating posts) and indirect (i.e., receiving feedback from users) effects of SNS (Valkenberg \& Peter, 2013). Selfperception theory (Bem, 1972) can undergird this hypothesis; it posits that a person can deduce their cognitions, beliefs, and attitudes by reflecting on their behavior. If a behavior is perceived to have occurred without coercion, the change in self-perception can become involuntarily internalized and result in a form of self-presentation that aligns with this new self-perception (Bem, 1972; Geusens \& Beullens, 2017). Geusens and Beullens (2017) assessed the self-generated media hypothesis by conducting a longitudinal study of late adolescents; those who reported sharing alcohol references at baseline were more likely to report binge drinking at baseline and a year later. Inversely, binge drinking at baseline also predicted future posting of alcohol content. These findings support a reciprocal temporal relationship with alcohol-related self-presentation on SNS, thereby emphasizing the importance of assessing self-presentation in relation to SNS use. 
Many young adults share alcohol posts on their SNS accounts (Erevik et al., 2017a; Hendriks et al., 2018), some of whom do so at least a few times a month (Geusens \& Beullens, 2017). An average of 26 alcohol references have been observed on college students' Facebook profiles (Ridout et al., 2012). Most of these references depict alcohol positively (Cavazos-Rehg et al., 2015) and receive more "likes" than posts without alcohol references (Hendriks et al., 2018). Positive alcohol posts seem to predict future alcohol consumption (Erevik et al., 2017b), although a meta-analysis indicated that greater SNS alcohol posting in general was associated with increased alcohol use (Curtis et al., 2018).

Although most past research specifically assesses how Facebook and alcohol use are related (Ridout et al., 2012; Westgate et al., 2014), studies have begun examining how drinking is associated with other SNS. Increased Instagram, Snapchat, and Twitter usage has been associated with greater binge drinking (Ceballos et al., 2018), and Snapchat is the SNS most strongly related to future drinking behaviors (Boyle et al., 2016).

SNSs are easily accessible on mobile phones; it is not surprising that college students use SNS while drunk (Wang et al., 2011). However, nearly $90 \%$ of them also reported engaging in drunk texting within the past 3 months, and almost $40 \%$ regretted doing so (Dunne \& Katz, 2015). Numerous studies have examined texting, yet drunk texting remains understudied despite its potential to serve as an example in alcohol reduction programs of a frequent low-risk drunken behavior that people subsequently regret (Dunne \& Katz, 2015). Approximately $20 \%$ of people who sent a Facebook message while intoxicated also regretted doing so (Dunne \& Katz, 2015); therefore, it is important to examine how use of other SNS platforms and the degree of openness with which content is shared may inform the relationship between alcohol consumption and drunk texting.

Social media addiction is an emerging construct given the novelty of SNS. Addictive use differs from regular use when it meets several components inherent to addictive behaviors (i.e., salience, mood modification, tolerance, withdrawal, conflict, relapse; Griffiths, 2005). The application of these addiction constructs to social media use is increasing (Andreassen et al., 2016). Even though greater social media addiction has been associated with increased alcohol consumption (Ceballos et al., 2018) and, as previously described, alcohol use is associated with posting alcoholrelated content, social media addiction has not been directly examined in relation to sharing alcohol posts.

Previous studies have observed that $9.9 \%$ of Chinese undergraduates met the conservative criteria for addictive social media use (Hou et al., 2019), and 59\% of US undergraduates reported feeling addicted to SNS (Cabral, 2011). Although studies have assessed social media addiction in different cultures (Wolniczak et al., 2013; Wu et al.,
2013), only one has directly compared Hispanics and nonHispanics (Ceballos et al., 2018). A total of 424 Hispanic and non-Hispanic undergraduates completed an online survey measuring alcohol use, social media addiction, social media use during and after the consumption of alcohol, and the frequency with which they used Facebook, Snapchat, Twitter, and Instagram. Higher social media addiction scores were associated with greater use of Instagram, Twitter, and Snapchat. The relationship between social media addiction and binge drinking approached statistical significance such that binge drinkers scored higher than non-binge drinkers. However, social media addiction did not differ between the two ethnicities (Ceballos et al., 2018).

Almost 70\% of Hispanics, the fastest growing and youngest US ethnic group (Lopez et al., 2018), have reported using at least one SNS (Lopez et al., 2013). In addition, nearly $25 \%$ of Hispanics ages 16 to 25 reported daily SNS use (Livingston \& Lopez, 2010). Although Hispanics may not be more susceptible to social media addiction than nonHispanics (Ceballos et al., 2018), they differ in other addictive behaviors.

Hispanic college students have reported less binge drinking than non-Hispanics (Ceballos et al., 2018). However, studies that measure binge drinking may overlook students with subthreshold problematic drinking habits. Past month hazardous drinking (i.e., alcohol consumption leading to a negative consequence; $26 \%$ ) seems more prevalent among Hispanic college students than binge drinking (17\%; Des Rosiers et al., 2013). Moreover, almost 65\% of Hispanic women reported consuming up to 7 weekly alcoholic drinks and men up to 14 weekly drinks, therefore being at some risk of alcohol use disorder (Des Rosiers et al., 2013). Cultural constructs (e.g., familism) were not associated with problem drinking among Hispanic undergraduates (Venegas et al., 2012). This study therefore did not include any cultural measures, but it sought to address the former issue by measuring the number of monthly drinks consumed instead of the number of binge drinking episodes.

Comparable to rates among all youth ages 18 to 29 , $96 \%$ of Hispanics within the same age range own a cell phone (Lopez et al., 2013). Although Hispanics send and receive texts less frequently than Whites (Livingston, 2011), approximately $50 \%$ of Hispanic youth text daily (Livingston \& Lopez, 2010). Despite the respectable amount of literature examining alcohol use and alcohol interventions among Hispanics, there remains a dearth of studies assessing engagement in drunk texting among this population. As previously mentioned, alcohol programs targeting Hispanics could use the regret often accompanying this behavior as a modern example of adverse alcohol consequences (Dunne \& Katz, 2015). However, in order to do so, it is important to investigate the frequency and associations of drunk texting among Hispanics. Therefore, the current study explored the 
relationship between quantity of alcoholic drinks and the novel behaviors of SNS use and texting among Hispanic college students.

Previous studies have examined the frequency and intensity of SNS use, but none have measured the amount of time spent on each site. Therefore, this study aimed to examine the relationships between SNS habits, posting alcohol references, and drunk texting among Hispanic college students. Consistent with previous literature (Curtis et al., 2018; Trub \& Starks, 2017), average monthly alcohol consumption was expected to be positively associated with sharing alcohol posts and drunk texting. Higher average weekly hours spent on SNS were also expected to relate to increased shared alcohol references and greater drunk texting.

\section{Methods}

\section{Participants}

The sample consisted of Hispanic students enrolled in a university on the US/Mexico border $(n=620,71.6 \%$ female; Mage $=21.07$ years, $S D=3.60$ ). Although the age range was between 18 and 52, almost $80 \%$ of participants were aged 18 to 22. Hispanic subgroups were not measured in the present study, but approximately $70 \%$ of students at this campus have self-identified as Mexican-American in past studies (Gutierrez \& Cooper, 2014). Most participants reported living with parents (83.5\%) and owning an iPhone (78.8\%). The inclusion criterion was that participants be over 18 years and taking a course within the Psychology Department.

\section{Measures}

Demographics. This questionnaire collected typical demographic information (e.g., participant age, gender).

Drug Use Frequency. This 36-item questionnaire assessed the age of first use and use frequency of various drugs (e.g., alcohol, marijuana) over the past month, year, and lifetime using the following prompt: "Please indicate how many times you have used [the substance] in your lifetime...in the past year...in the past 30 days." Previous research has used similar measures to assess drug use frequency (Gutierrez \& Cooper, 2014, 2016).

Texting Under the Influence Scale. This five-item scale assesses the frequency of drunk texting within the past 30 days. Adequate internal consistency was observed in previous studies ( $a=0.90$; Trub \& Starks, 2017) and presently $(a=0.909)$. Answer choices for how frequently individuals engaged in different drunk texting behaviors ranged from "0" to " $20+$." Each answer choice was scored between 0 and 4 , and all were averaged to create a mean composite. Higher scores suggested increased drunk texting within the past 30 days.

Strategic Self Presentation Scale. This 4-item scale assesses how often participants privately $(a=0.740)$ or publicly $(a=0.926)$ shared: images referring to alcohol use, textual updates referencing alcohol, images in which they were drunk, and textual updates while they were drunk ( $\alpha=0.913$; Geusens \& Beullens, 2017). The meanings of "private" and "public" sharing were interpreted by the participants, although it is generally understood that private sharing is more limited and direct (Geusens \& Beullens, 2017). Items were rated on a 7-point Likert scale $(0=$ Never, $6=$ Several Times a Day). Public posting items received a score of 0 , and items encompassing private posting received a score of 1 . Items were averaged to create a mean composite for private self-presentation and public self-presentation. High scores on each subscale indicated an increased tendency to privately or publicly share alcohol posts, respectively.

\section{Sharing of Alcohol-Related Content on Social Networking}

Sites. This 7-item scale assessed how frequently participants shared alcohol references and consequences expressed in these posts (Erevik et al., 2017a). The scale was adapted to include an initial item asking participants if they had ever posted any alcohol references on SNS. Despite this adaptation, the scale maintained adequate internal consistency, $a=0.862$. The remaining items comprised six single-item subscales: drinking for relaxation, consuming alcoholic drinks at a social gathering, drinking alone, referring to positive consequences of alcohol use, referring to negative consequences of alcohol consumption, drinking on weekdays. Infrequent posting ranged from "never" to "less than once a month" and received a score of 0 . Frequent posting ranged from "monthly" to "daily or almost daily" and received a score of 1 .

BSMAS. Each of the six Bergen Social Media Addiction Scale (BSMAS) items represents a core component of addiction (Andreassen et al., 2017). Items were scored on a 5-point Likert scale $(1=$ Very Rarely, $5=$ Very Often $)$ and averaged to create a mean composite in which higher scores indicated greater social media addiction. Social media addiction was conservatively classified as scoring 3 or above on all six items (Andreassen et al., 2012). Adequate internal consistency was observed in current $(a=0.828)$ and past studies (Andreassen et al., 2016; Hou et al., 2019).

iPhone Screen Time Measure. This 20 -item questionnaire was created for the current study to obtain an objective measure of participants' screen time, SNS use, number of times picking up their phones, and number of notifications received over 
the past week, $a=0.793$. Screen time was only measured for participants with iPhone because the feature comes with the phone by default, whereas on Android devices, a screen time app needs to be installed. The first item asked participants if they had an iPhone; those who answered "no" were instructed to skip the remaining items and begin the next measure. Participants with iPhones were provided instructions on how to access the screen time information on their phones to answer the following weekly and daily usage items: screen time, Instagram, Snapchat, Facebook, Twitter, Messaging app, Tinder, total pickups, total notifications. The "total hours on SNS" item only assessed hours in the past week.

\section{Procedure}

Approval was obtained from the university IRB prior to data collection. Students who signed up to participate in the study on SONA, a web-based recruitment site, read and electronically signed a consent form before commencing the survey (not linked to the consent form). Upon completing the online assessment, participants received research participation credit. Data were collected from February 12, 2019 to May 10, 2019.

\section{Approach to Analyses}

Descriptive analyses assessed participant characteristics. Inferential analyses, however, included only iPhone users to eliminate reliance on self-reported SNS and individual platform use. Bivariate correlations were conducted between all of the variables included in regression analyses. Six logistic regressions assessed the relationships between the six subscales of alcoholrelated posts as the dependent variables and the following independent variables: average monthly alcohol use, mean weekly hours of SNS use, public and private strategic self-presentation, and average BSMAS total. A linear regression was conducted on the dependent variable drunk texting. For this regression, model predictors included average monthly alcohol use; public and private strategic self-presentation; the average BSMAS total; mean weekly hours spent using Facebook, Instagram, Snapchat, Twitter; and the phone text messaging application. Age and gender were included as covariates in all seven regression analyses. Gender was dummy coded $($ men $=0$, women $=1)$.

\section{Results}

Participants averaged 5 alcoholic drinks per month $(S D=8.83$; Table 1$)$. iPhone users spent an average of $16.84 \mathrm{~h}$ per week $(S D=17.29)$ on SNS. Ever sharing of alcohol references on SNS was reported by $39.2 \%$ of participants, and $14.7 \%$ of participants scored above the social media addiction threshold on the BSMAS. The most commonly shared alcohol posts on a weekly basis implied drinking at a social gathering and drinking for relaxation and/or taste (Table 2). Approximately $20 \%$ of the sample engaged in each type of texting under the influence behavior at least once in the past month.

All types of alcohol posts had moderate positive associations with texting under the influence ( $r$ 's $=0.262-0.445$ ), moderate to large positive associations with both public ( $r$ 's $=0.387-0.617)$ and private $(r ' s=0.303-0.647)$ sharing of posts, and small positive associations with social media addiction ( $r$ 's $=0.157-0.206$ ). Greater alcohol consumption was weakly associated with frequent sharing of posts about drinking for relaxation and/or taste $(r=0.224, p=0.001)$, drinking at a social gathering $(r=0.253, p<0.001)$, drinking on weekdays $(r=0.282, p<0.001)$, and drunk texting $(r=0.204, p<0.001)$. A small but statistically significant association between men and sharing posts about drinking alone $(r=-0.151, p=0.011)$ also emerged.

Texting under the influence had small positive associations with age $(r=0.084, p=0.023)$, alcohol use $(r=0.204, p<0.001)$, time spent on Twitter $(r=0.151, p=0.001)$, and social media addiction $(r=0.181, p<0.001)$. Greater public sharing of posts $(r=0.387, p<0.001)$ was moderately associated with drunk texting, while more private self-presentation $(r=0.521, p<0.001)$ was strongly associated with texting under the influence.

The first logistic regression model that assessed the relaxation subscale was statistically significant, $\chi^{2}(7)=24.540$, $p<0.001$ (Table 3). Higher scores on the BSMAS were associated with greater sharing of posts relating alcohol to relaxation $(O R=1.139, p<0.05)$. The second logistic regression model for the social gathering subscale was statistically significant, $\chi^{2}(7)=46.645, p<0.001$. Participants who frequently shared alcohol content privately $(O R=5.330, p<0.01)$ and

Table 1 Participant characteristics and descriptive statistics

\begin{tabular}{ll}
\hline Participants $(n=620)$ & \\
\hline Characteristic/variable & Frequency/mean (SD) \\
Age & $M=21.07(3.60)$ \\
Female & $73.5 \%$ \\
Male & $25.8 \%$ \\
Living with parents & $83.5 \%$ \\
Ever posted alcohol references on SNS & $39.2 \%$ \\
Social media addiction prevalence & $14.7 \%$ \\
Social media addiction & $15.99(5.19)$ \\
Monthly alcohol use (drinks) & $5.10(8.83)$ \\
Weekly social media use (hours) & $16.84(17.29)$ \\
Weekly Facebook use & $3.86(11.19)$ \\
Weekly Messaging app & $6.81(18.00)$ \\
Weekly Instagram use & $7.02(12.10)$ \\
Weekly Snapchat use & $4.97(11.61)$ \\
Weekly Twitter use & $3.29(6.70)$ \\
\hline
\end{tabular}

Weekly use of all social media platforms was measured in hours 
Table 2 Frequency of sharing alcohol posts on SNS and engaging in drunk texting behaviors

Sharing of Alcohol-Related Content on Social Networking Sites

\begin{tabular}{|c|c|c|c|}
\hline Posting content suggestive of... & Weekly & Monthly & Less than Monthly \\
\hline Relaxation and/or taste & $3.2 \%$ & $10.3 \%$ & $65.9 \%$ \\
\hline Drinking at a social gathering & $2.5 \%$ & $12.0 \%$ & $58.9 \%$ \\
\hline Drinking on weekdays & $1.8 \%$ & $6.7 \%$ & $47.7 \%$ \\
\hline Drinking alone & $0 \%$ & $2.5 \%$ & $32.8 \%$ \\
\hline Positive consequences of alcohol & $0.7 \%$ & $4.6 \%$ & $41.5 \%$ \\
\hline Negative consequences of alcohol & $0.8 \%$ & $3.6 \%$ & $41.4 \%$ \\
\hline \multicolumn{4}{|l|}{ Texting Under the Influence } \\
\hline How often, while drunk, have you... & $1-2$ times & $3-10$ times & $11+$ times \\
\hline Sent a text which led you to do something you wouldn't have done sober? & $18.8 \%$ & $6.8 \%$ & $1.8 \%$ \\
\hline Sent a text to someone you would not have contacted otherwise? & $18.8 \%$ & $3.6 \%$ & $1.5 \%$ \\
\hline Sent a message that you might not have sent when sober? & $20.2 \%$ & $6.5 \%$ & $2.1 \%$ \\
\hline Used your phone to send a text? & $19.9 \%$ & $18.1 \%$ & $10.7 \%$ \\
\hline Thought about sending a text that you might not have sent when sober? & $21.4 \%$ & $10.7 \%$ & $6.0 \%$ \\
\hline
\end{tabular}

The difference between the summed values listed for each type of alcohol post, and $100 \%$ is the number of participants who never shared that type of post. The values for the texting under the influence measure indicate the frequency within the past 30 days

obtained high BSMAS scores $(O R=1.189, p<0.05)$ were more likely to post content implying they consumed alcoholic drinks at a social gathering. Higher alcohol use $(O R=1.1093$, $p=0.054)$ approached significance in this second model. The third logistic regression model that assessed weekday drinking was statistically significant, $\chi^{2}(7)=27.561, p<0.001$. Participants who consumed more alcohol $(O R=1.147$, $p<0.01$ ) were more likely to share posts indicating weekday alcohol use. The fourth logistic regression model predicting drinking alone was statistically significant, $\chi^{2}(7)=21.071$, $p<0.01$. Frequently sharing alcohol posts implying drinking alone was associated with greater public sharing of alcohol references $(O R=19.630, p<0.05)$, higher BSMAS scores $(O R=1.475, p<0.05)$, and higher mean weekly hours of SNS use $(O R=1.053, p<0.05)$. The models for the positive and negative consequences subscales were not statistically significant, thus not included in Table 3.

The linear regression assessing drunk texting was statistically significant, $F(11)=5.869, R^{2}=0.262, p<0.001$ (Table 4) and suggested that participants' drunk texting was associated with being older $(\beta=0.136, p<0.05)$, spending more time on Instagram $(\beta=0.386, p<0.01)$, and privately sharing alcohol posts more frequently $(\beta=0.299, p<0.01)$. Participants with higher Facebook use were less likely to drunk text $(\beta=-392, p<0.01)$.

\section{Discussion}

Approximately $40 \%$ of participants reported ever posting alcohol content on SNS, similar to rates reported in previous studies (Geusens \& Beullens, 2017; Moreno et al., 2012). The most frequently shared posts were about drinking at social gatherings. The average amount of time spent on SNS per week was higher than previously reported among a similar sample of Hispanic undergraduates (46 h/month; Gutierrez \& Cooper, 2016), suggesting that social media use has dramatically increased within the past few years.

Partially consistent with past findings (e.g., Curtis et al., 2018), alcohol consumption was associated with more frequent sharing of posts about relaxation and/or taste, drinking at social gatherings, and drinking on weekdays. However, after controlling for age, gender, weekly social media use, types of self-presentation, and social media addiction, alcohol use emerged as a predictor for posts about drinking on weekdays. These findings suggest that the relationship between drinking and sharing alcohol posts is related to the content of the posts being shared. Of note, these relationships were weaker than those reported in previous studies (Curtis et al., 2018), potentially due to the low frequency of alcohol consumption observed in this sample. This is likely because students' environment was not conducive to drinking; they attended a commuter-heavy university, and most lived with their parents (consistent with previous studies of Mexican American young adults; see Landale et al., 2006), characteristics which have been noted to result in less drinking among college students (Benz et al., 2017). Despite this low level pattern of drinking, increasing consumption was associated with posting about drinking on weekdays, a problematic drinking pattern (Lau-Barraco et al., 2016). Doing so may be related to efforts at normalizing the behavior, attention seeking, gaining peer acceptance, or assuaging negative affect. Assessing potential motives for sharing alcohol-related content in future studies and perhaps doing 
Table 3 Summaries of four logistic regression models predicting sharing of alcoholrelated content

\begin{tabular}{|c|c|c|c|c|c|}
\hline \multirow[t]{2}{*}{ Variable } & \multirow[t]{2}{*}{$\beta$} & \multirow[t]{2}{*}{ SE $\beta$} & \multirow[t]{2}{*}{ OR } & \multicolumn{2}{|l|}{$95 \% \mathrm{CI}$} \\
\hline & & & & Lower & Upper \\
\hline \multicolumn{6}{|c|}{ Model 1: Predictors of SARC regarding relaxation and/or taste } \\
\hline Gender & -0.699 & 0.624 & 0.497 & 0.146 & 1.690 \\
\hline Age & 0.096 & 0.092 & 1.101 & 0.918 & 1.320 \\
\hline Monthly alcohol use & 0.058 & 0.040 & 1.060 & 0.980 & 1.146 \\
\hline Weekly social media use & 0.011 & 0.012 & 1.011 & 0.987 & 1.036 \\
\hline Public strategic self-presentation & 0.351 & 0.470 & 1.421 & 0.566 & 3.571 \\
\hline Private strategic self-presentation & 0.329 & 0.447 & 1.390 & 0.579 & 3.336 \\
\hline BSMAS & 0.130 & 0.059 & 1.139 & 1.014 & 1.280 \\
\hline Constant & -6.098 & 2.730 & 0.002 & & \\
\hline \multicolumn{6}{|c|}{ Model 2: Predictors of SARC regarding a social gathering } \\
\hline Gender & -0.172 & 0.789 & 0.842 & 0.179 & 3.957 \\
\hline Age & 0.142 & 0.105 & 1.152 & 0.939 & 1.414 \\
\hline Monthly alcohol use & $0.089 \dagger$ & $0.046 \dagger$ & $1.093 \dagger$ & $0.999 \dagger$ & $1.196 \dagger$ \\
\hline Weekly social media use & 0.007 & 0.015 & 1.007 & 0.979 & 1.037 \\
\hline Public strategic self-presentation & 0.108 & 0.552 & 1.114 & 0.378 & 3.284 \\
\hline Private strategic self-presentation & 1.673 & 0.593 & $\mathbf{5 . 3 3 0}$ & 1.668 & 17.026 \\
\hline BSMAS & 0.173 & 0.069 & 1.189 & 1.038 & 1.362 \\
\hline Constant & -10.532 & 3.407 & $\mathbf{0 . 0 0 0}$ & & \\
\hline \multicolumn{6}{|c|}{ Model 3: Predictors of SARC regarding drinking on weekdays } \\
\hline Gender & 0.066 & 0.867 & 1.068 & 0.195 & 5.839 \\
\hline Age & 0.024 & 0.124 & 1.025 & 0.803 & 1.308 \\
\hline Monthly alcohol use & 0.137 & 0.052 & 1.147 & 1.036 & 1.269 \\
\hline Weekly social media use & 0.005 & 0.016 & 1.005 & 0.975 & 1.036 \\
\hline Public strategic self-presentation & 0.631 & 0.564 & 1.879 & 0.622 & 5.679 \\
\hline Private strategic self-presentation & 0.203 & 0.530 & 1.225 & 0.434 & 3.458 \\
\hline BSMAS & 0.109 & 0.074 & 1.115 & 0.964 & 1.289 \\
\hline Constant & -6.642 & 3.826 & 0.001 & & \\
\hline \multicolumn{6}{|c|}{ Model 4: Predictors of SARC regarding drinking alone } \\
\hline Gender & -1.487 & 1.389 & 0.226 & 0.015 & 3.440 \\
\hline Age & 0.020 & 0.298 & 1.020 & 0.569 & 1.830 \\
\hline Monthly alcohol use & -0.032 & 0.080 & 0.968 & 0.828 & 1.132 \\
\hline Weekly social media use & 0.051 & $\mathbf{0 . 0 2 0}$ & $\mathbf{1 . 0 5 3}$ & 1.012 & 1.095 \\
\hline Public strategic self-presentation & 2.977 & 1.279 & 19.630 & 1.599 & 240.963 \\
\hline Private strategic self-presentation & -1.470 & 1.050 & 0.230 & 0.029 & 1.799 \\
\hline BSMAS & 0.389 & $\mathbf{0 . 1 7 7}$ & 1.475 & 1.043 & 2.086 \\
\hline Constant & -12.252 & 8.457 & 0.000 & & \\
\hline
\end{tabular}

Bold text indicates significance at $p<0.05$

$S A C$ sharing alcohol-related content so in non-student Hispanic young adults seems warranted. While these data were collected prior to the COVID-19 pandemic and subsequent restrictions, given the recent and potentially lingering increase in social isolation and time spent on social media due to the pandemic (Cooper et al., 2020a, 2020b), the reciprocal relationship between alcohol use and sharing alcohol-related content (Geusens \& Beullens, 2017) appears a timely avenue for future assessment as well.

Partially consistent with the initial hypothesis, greater social media use was also related in a weak to moderate fashion to more frequently sharing alcohol posts about drinking for relaxation and/or taste, drinking at social gatherings, drinking alone, and negative alcohol consequences in bivariate analyses. Among these, in multivariate analyses, only the relationship between greater social media use and drinking alone posting was observed. However, multivariate analyses revealed relationships between social media addiction and sharing posts referencing drinking for relaxation and/or taste, drinking at a social gathering, and drinking alone. The relationship between SNS addiction and pleasure-related 
Table 4 Linear regression model predicting texting under the influence

\begin{tabular}{lrrr}
\hline Variable & \multicolumn{1}{l}{$B$} & \multicolumn{1}{l}{$S E$} & \multicolumn{1}{l}{$\beta$} \\
\hline Gender & -0.191 & 0.119 & -0.106 \\
Age & $\mathbf{0 . 0 3 6}$ & $\mathbf{0 . 0 1 8}$ & $\mathbf{0 . 1 3 6}$ \\
Monthly alcohol use & 0.003 & 0.006 & 0.033 \\
Weekly Facebook use & $\mathbf{- 0 . 0 2 3}$ & $\mathbf{0 . 0 0 8}$ & $\mathbf{- 0 . 3 9 2}$ \\
Weekly Messaging app & -0.003 & 0.004 & -0.065 \\
Weekly Instagram use & $\mathbf{0 . 0 2 1}$ & $\mathbf{0 . 0 0 7}$ & $\mathbf{0 . 3 8 6}$ \\
Weekly Snapchat use & -0.001 & 0.006 & -0.016 \\
Weekly Twitter use & 0.012 & 0.007 & 0.116 \\
Public strategic self - presentation & 0.112 & 0.119 & 0.088 \\
Private strategic self - presentation & $\mathbf{0 . 3 2 4}$ & $\mathbf{0 . 1 0 0}$ & $\mathbf{0 . 2 9 9}$ \\
BSMAS & 0.014 & 0.011 & 0.087 \\
Constant & -0.152 & 0.504 & \\
\hline
\end{tabular}

$R^{2}=0.262, F(11)=5.869, p<0.001$. Bold text indicates significance at $p<0.05$

alcohol posting is consistent with high-risk internet use associations with socialization and enhancement internet use motives (Bischof-Kastner et al., 2014). Alternatively, the relationship between SNS addiction and posting about drinking alone is consistent with findings noting a relationship between SNS addiction and internet use coping motives (Lerma et al., in press). Thus, as was the case with the relationships observed with posting weekday drinking content, taken together, these findings suggest the need for future studies to assess in a nuanced manner social networking motives and not only their relationship to SNS use and addiction but also their associations with posting alcoholrelated content and drinking itself.

Consistent with the self-generated media hypothesis, the moderate and strong associations evident between all types of alcohol posts and both public and private forms of self-presentation suggest that in this study, Hispanic college students gain selfrelated and/or other added value from alcohol-related sharing (Valkenberg \& Peter, 2013), despite a lack of reported excessive drinking. That students were more likely to publicly post content referring to drinking alone yet privately share posts about drinking at a social gathering suggests a dichotomy not yet identified in the literature. This finding may indicate a difference in self-perception and motivation between students sharing each type of post. Students who privately shared posts about drinking at social gatherings may post this content primarily to connect with friends. In contrast, Hispanic students who publicly posted about drinking alone may be using SNS for coping motives because, as previously propositioned, this content may be a way for Hispanic students to seek social support. Again, future studies should explore the relationship between internet/social networking motives, self-presentation, and types of alcohol posts in a theory-driven manner.
Consistent with hypotheses, drunk texting was associated with alcohol use in bivariate analyses, although it did not emerge as a statistically significant predictor after controlling for other variables. In multivariate analyses, drunk texting was associated with older age, privately sharing alcohol posts, and differing time spent on Facebook and Instagram. The average age in the sample was 21 ; therefore, drinking alcohol for them was both legal and more accessible than it would be for underage college students. More frequent drunk texting may be associated with greater time spent on Instagram than on Facebook because Instagram's imagebased design facilitates exposure to alcohol content, which has been observed to predict current and future alcohol consumption (Boyle et al., 2016). Lastly, as social media is readily accessible on mobile phones that also allow for texting, generally to keep in touch with friends and family (Lenhart, 2010), it is fitting that sending private alcohol-related messages on SNS was related to drunk texting. Presently, the almost indiscernible relationship between cell phone and SNS use, and indeed that the present study focused on SNS use via students' iPhones, suggests the potential for ecological momentary assessments in future studies.

Limitations include the use of a convenience sample with an overrepresentation of females, potentially limiting generalizability, and use of self-report. However, participants were assured anonymity to decrease socially desirable response bias. This study was also cross-sectional and retrospective, not allowing for the assessment of temporal relationships, necessitating a future prospective study and the potential use of ecological momentary assessment in real time (e.g., number of drinks, frequency of social media use). In addition, posting and texting motives were not measured, neither was motivation to reduce sharing. Thus, future studies should assess these constructs to inform future prevention and intervention efforts. Lastly, the measure used for alcohol consumption did not capture drinking quantity in a sitting, so it is possible that although Hispanic students did not consume alcohol often, they may have engaged in binge drinking when they did consume it (Venegas et al., 2012).

Despite limitations, this study has multiple strengths. It is among the first studies to use an objective "screen time" measure rather than relying on self-reported data. This is also the first study to measure the frequency in which specific alcohol posts are shared and behaviors related to texting under the influence occur among Hispanics. Furthermore, the participant sample was composed of a relatively homogenous group of Hispanics, specifically Mexican-Americans; the findings are therefore likely applicable to an ethnic subgroup that comprises $63 \%$ of the Hispanic population in the USA (Flores et al., 2015). However, extending this assessment to other Hispanic and/ or ethnoculturally diverse groups is suggested. 
Results suggest several potential implications for intervention efforts related to alcohol or SNS. Drinking alone and drinking to relax are included as criteria for problem drinking in the CRAFFT screening tool and are in fact two of the key words in the mnemonic of the scale-Car, Relax, Alone, Forget, Friends, Trouble (Knight et al., 1999). This connection suggests that posts referencing these behaviors may be used to identify at-risk SNS users (Moreno et al., 2012). In addition, social media interventions may use these words and their synonyms to target users who share problematic drinking posts. This method may be used across platforms and thus allow for the creation of a general online intervention program, rather than one suited to each social media platform (Moreno et al., 2016). Privacy concerns are also important; as such, posts about drinking alone may be particularly suited for targeting potential problem drinkers due to the likelihood these posts have been publicly shared. During COVID-19, average social media addiction scores similar to those in this study have been reported among college students (Arslan et al., 2021), although the amount of time spent on SNS tends to be even greater than that reported in the present study (Zhao \& Zhou, 2020). That social media use frequency has been associated with adherence to COVID-19 guidelines yet social media addiction is inversely related with adherence (Cooper et al., 2020a, 2020b) suggests that redirecting college students to seemingly healthier uses of social media (while not crossing into the addictive use range) seems optimal to enhance both individual and public health.

Findings also have important implications for research within the domains of alcohol and technology usage, as the clearly excessive SNS use and observed relationships with alcohol posting and texting suggest the likelihood of an emerging behavioral addiction and its co-use with alcohol, a more traditional addictive behavior. Future prospective studies of these relationships in Hispanic college and noncollege student and/or diverse ethnocultural groups, which further assess user motives and intentions to reduce these behaviors, will likely inform prevention and intervention efforts to promote more moderate drinking and more adaptive SNS behaviors.

Acknowledgements The authors would like to acknowledge all past and current members of the Prevention and Treatment in Clinical Health laboratory for their assistance with this study.

\section{Declarations}

Ethical Approval IRB approval was obtained before commencing the study and participants who opted to sign up for the study read and electronically signed a consent form before beginning the survey.

Competing Interests The authors declare no competing interests.

\section{References}

Andreassen, C. S., Billieux, J., Griffiths, M. D., Kuss, D. J., Demetrovics, Z., Mazzoni, E., \& Pallesen, S. (2016). The relationship between addictive use of social media and video games and symptoms of psychiatric disorders: a large-scale cross-sectional study. Psychology of Addictive Behaviors, 30(2), 252-262. https://doi.org/10. 1037/adb0000160

Andreassen, C. S., Pallesen, S., \& Griffiths, M. D. (2017). The relationship between addictive use of social media, narcissism, and selfesteem: findings from a large national survey. Addictive Behaviors, 64, 287-293. https://doi.org/10.1016/j.addbeh.2016.03.006

Andreassen, C. S., Torsheim, T., Brunborg, G. S., \& Pallesen, S. (2012). Development of a facebook addiction scale. Psychological Report, 110(2), 501-517. https://doi.org/10.2466/02.09.18. PR0.110.2.501-517

Arslan, G., Yıldırım, M., \& Zangeneh, M. (2021). Coronavirus anxiety and psychological adjustment in college students: exploring the role of college belongingness and social media addiction. International Journal of Mental Health Addiction. https://doi.org/10. 1007/s11469-020-00460-4

Bem, D. J. (1972). Self-perception theory. In S. Kassin, S. Fein, \& H. R. Markus (Eds.), Social Psychology. (10th ed., pp. 60-62). Cengage Learning.

Benz, M. B., DiBello, A. M., Balestrieri, S. G., Miller, M. B., Merrill, J. E., Lowery, A. D., Mastroleo, N. R., \& Carey, K. B. (2017). Off-campus residence as a risk-factor for heavy drinking among college students. Substance Use \& Misuse, 52(9), 1236-1241. https://doi.org/10.1080/10826084.2017.1298620

Bischof-Kastner, C., Kuntsche, E., \& Wolstein, J. Ö. (2014). Identifying problematic internet users: development and validation of the internet motive questionnaire for adolescents (IMQ-A). Journal of Medical Internet Research, 16(10), e230. https://doi.org/10. 2196/jmir.3398

Boyle, S. C., LaBrie, J. W., Froidevaux, N. M., \& Witkovic, Y. D. (2016). Different digital paths to the keg? How exposure to peers' alcohol-related social media content influences drinking among male and female first-year college students. Addictive Behaviors, 57, 21-29. https://doi.org/10.1016/j.addbeh.2016.01.011

Cabral, J. (2011). Is generation Y addicted to social media? The Elon Journal of Undergraduate Research in Communications, 2(1), $5-14$.

Cavazos-Rehg, P. A., Krauss, M. J., Sowles, S. J., \& Bierut, L. J. (2015). "Hey everyone, I'm drunk." An evaluation of drinkingrelated Twitter chatter. Journal of Studies on Alcohol and Drugs, 76(4), 635-643. https://doi.org/10.15288/jsad.2015.76.635

Ceballos, N. A., Howard, K., Dailey, S., Sharma, S., \& Grimes, T. (2018). Collegiate binge drinking and social media use among Hispanics and Non-Hispanics. Journal of Studies on Alcohol and Drugs, 79(6), 868-875. https://doi.org/10.15288/jsad.2018.79.868

Cooper, T.V., Lerma, M., Sagaribay, R., Woloshchuk, C.J., \& Eno Louden, J. (2020b). COVID-19 perceptions of seriousness, risk, and adherence to guidelines in college students on the border of the U.S. and Mexico. Manuscript submitted for publication.

Cooper, T.V., Lerma, M., Woloshchuk, C.J., Sagaribay, R., Sandoval, K., \& Eno Louden, J. (2020a). Health and mental health associations with COVID-19 perceptions of seriousness, risk, and adherence to containment guidelines. Manuscript submitted for publication.

Curtis, B. L., Lookatch, S. J., Ramo, D. E., McKay, J. R., Feinn, R. S., \& Kranzler, H. R. (2018). Meta-analysis of the association of alcohol-related social media use with alcohol consumption and alcohol-related problems in adolescents and young adults. Alcoholism: Clinical and Experimental Research, 42(6), 978-986. https://doi.org/10.1111/acer.13642 
Des Rosiers, S. E., Schwartz, S. J., \& Zamboanga, B. L. (2013). A cultural and social cognitive model of differences in acculturation orientations, alcohol expectancies, and alcohol-related risk behaviors among Hispanic college students. Journal of Clinical Psychology, 69(4), 319-340. https://doi.org/10.1002/jclp.21859

Dunne, E. M., \& Katz, E. C. (2015). Alcohol outcome expectancies and regrettable drinking-related social behaviors. Alcohol and alcoholism, 50(4), 393-398. https://doi.org/10.1093/alcalc/agv026

Erevik, E. K., Torsheim, T., Vedaa, O., Andreassen, C. S., \& Pallesen, S. (2017a, May). Sharing of alcohol-related content on social networking sites: frequency, content, and correlates. Journal of Studies on Alcohol and Drugs, 608-616. https://doi.org/10.15288/ jsad.2017.78.608

Erevik, E. K., Torsheim, T., Andreassen, C. S., Vedaa, O., \& Pallesen, S. (2017b). Disclosure and exposure of alcohol on social media and later alcohol use: a large-scale longitudinal study. Frontiers in Psychology, 8, 1-11. https://doi.org/10.3389/fpsyg.2017.01934

Flores, A., Lopez, G., \& Radford, J. (2015, September 18). 2015, Hispanic population in the United States statistical portrait. Retrieved from https://www.pewresearch.org/hispanic/2017/09/ 18/2015-statistical-information-on-hispanics-in-united-statescurrent-data/

Geusens, F., \& Beullens, K. (2017). The reciprocal associations between sharing alcohol references on social networking sites and binge drinking: a longitudinal study among late adolescents. Computers in Human Behavior, 73, 499-506. https://doi.org/10. 1016/j.chb.2017.03.062

Griffiths, M. (2005). A 'components' model of addiction within a biopsychosocial framework. Journal of Substance Use, 10(4), 191-197. https://doi.org/10.1080/14659890500114359

Gutierrez, K. M., \& Cooper, T. V. (2014). Investigating correlates of synthetic marijuana and Salvia use in light and intermittent smokers and college students in a predominantly Hispanic sample. Experimental and Clinical Psychopharmacology, 22(6), 524-529. https://doi.org/10.1037/a0038014

Gutierrez, K. M., \& Cooper, T. V. (2016). The use of social networking sites: a risk factor for using alcohol, marijuana, and synthetic cannabinoids? Drug and Alcohol Dependence, 163, 247-250. https:// doi.org/10.1016/j.drugalcdep.2016.03.021

Hendriks, H., van den Putte, B., Gebhardt, W. A., \& Moreno, M. A. (2018). Social drinking on social media: content analysis of the social aspects of alcohol-related posts on Facebook and Instagram. Journal of Medical Research, 20(6). https://doi.org/10.2196/jmir. 9355

Hoffman, E. W., Weintraub Austin, E., Pinkleton, B. E., \& Austin, B. W. (2017). An exploration of the associations of alcohol-related social media use and message interpretation outcomes to problem drinking among college students. Health Communication, 32, 865-871. https://doi.org/10.1080/10410236.2016.1195677

Hou, Y., Xiong, D., Jiang, T., Song, L., \& Wang, Q. (2019). Social media addiction: its impact, mediation, and intervention. Cyberpsychology: Journal of Psychosocial Research on Cyberspace, 13(1), article 4. https://doi.org/10.5817/CP2019-1-4

Knight, J. R., Shrier, L. A., Bravender, T. D., Farrell, M., Vander Bilt, J., \& Shaffer, H. J. (1999). A new brief screen for adolescent substance abuse. Archives of Pediatric and Adolescent Medicine, 153, 591-596. https://doi.org/10.1001/archpedi.153.6.591

Landale, N. S., Salvador Oropesa, R., \& Bradatan, C. (2006). Hispanic families in the United States: family structure and process in an era of family change. In M. Tienda \& F. Mitchell (Eds.), Hispanics and the future of America. National Academies Press.

Lau-Barraco, C., Braitman, A. L., Linden-Carmichael, A. N., \& Stamates, A. L. (2016). Differences in weekday versus weekend drinking among nonstudent emerging adults. Experimental and Clinical Psychopharmacology, 24(2), 100-109. https://doi.org/10.1037/pha0000068
Lenhart, A. (2010, September 2). Cell phones and American adults. Retrieved from https://www.pewresearch.org/internet/2010/09/02/ cell-phones-and-american-adults/

Lerma, M., Marquez, C., Sandoval, K., \& Cooper, T. V. (in press). Psychosocial correlates of excessive social media use in a Hispanic college sample. Cyberpsychology, Behavior, and Social Networking. https://doi.org/10.1089/cyber.2020.0498

Livingston, G. (2011, February 9). Latinos and digital technology. Retrieved from https://www.pewresearch.org/hispanic/2011/02/ 09/latinos-and-digital-technology-2010/

Livingston, G., \& Lopez, M. H. (2010, July 28). How young Latinos communicate with friends in the digital age. Retrieved from https://www.pewresearch.org/hispanic/2010/07/28/how-younglatinos-communicate-with-friends-in-the-digital-age/

Lopez, M. H., Gonzalez-Barrera, A., \& Pattern, E. (2013, March 7). Closing the digital divide. Retrieved from https://www.pewresearch. org/hispanic/wp-content/uploads/sites/5/2013/03/Latinos_Social_ Media_and_Mobile_Tech_03-2013_final.pdf

Lopez, M. H., Krogstad, J. M., \& Flores, A. (2018). Key facts about one of the nation's fastest growing populations. Retrieved from https://www.pewresearch.org/fact-tank/2018/09/13/key-factsabout-young-latinos/

Moreno, M. A., Christakis, D. A., Egan, K. G., Brockman, L. N., \& Becker, T. (2012). Associations between displayed alcohol references on Facebook and problem drinking among college students. Archives of Pediatrics and Adolescent Medicine, 166(2), 157-163. https://doi.org/10.1001/archpediatrics.2011.180

Moreno, M. A., D’Angelo, J., \& Whitehill, J. (2016). Social media and alcohol: Summary of research, intervention ideas and future study directions. Media and Communication, 4(3), 50-59. https://doi.org/ 10.17645/mac.v4i3.529

Ridout, B., Campbell, A., \& Ellis, L. (2012). 'Off your Faceb(book)': alcohol in online social identity construction and its relation to problem drinking in university students. Drug and Alcohol Review, 31, 20-26. https://doi.org/10.1111/j.1465-3362.2010. 00277.x

Trub, L., \& Starks, T. J. (2017). Texting under the influence: emotional regulation as a moderator of the association between binge drinking and drunk texting. Cyberpsychology, Behavior, and Social Networking, 20(1), 3-9. https://doi.org/10.1089/cyber.2016.0468

Valkenburg, P. M., \& Peter, J. (2013). Five challenges for the future of media-effects research. International Journal of Communication, 7, 197-215. http://ijoc.org/index.php/ijoc/article/download/ $1962 / 849$

Venegas, J., Cooper, T. V., Naylor, N., Hanson, B. S., \& Blow, J. A. (2012). Potential cultural predictors of heavy episodic drinking in hispanic college students. The American Journal on Addictions, 21(2), 145-149. https://doi.org/10.1111/j.1521-0391.2011. 00206.X

Wang, Y., Komanduri, S., Leon, P.G., Norcie, G., Acquisti, A., \& Cranor, L.F. (2011). I regretted the minute I pressed share: a qualitative study of regrets on Facebook. In Symposium on Usuable Privacy and Security (SOUPS), Pittsburgh, PA (July 20-22).

Westgate, E. C., Neighbors, C., Heppner, H., Jahn, S., \& Lindgren, K. P. (2014). "I will take a shot for every 'like' I get on this status": posting alcohol-related Facebook content is linked to drinking outcomes. Journal of Studies on Alcohol and Drugs, 75(3), 390398. https://doi.org/10.15288/jsad.2014.75.390

Wolniczak, I., Caceres-DelAguila, J. A., Palma-Ardiles, G., Arroyo, K. J., Solís-Visscher, R., Paredes-Yauri, S., \& Bernabe-Ortiz, A. (2013). Association between Facebook dependence and poor sleep quality: a study in a sample of undergraduate students in Peru. PLOS ONE, 8, e59087. https://doi.org/10.1371/journal.pone.0059087

Wu, A. M., Cheung, V. I., Ku, L., \& Hung, E. P. (2013). Psychological risk factors of addiction to social networking sites among Chinese 
smartphone users. Journal of Behavioral Addictions, 2, 160-166. https://doi.org/10.1556/JBA.2.2013.006

Zhao, N., \& Zhou, G. (2020). Social media use and mental health during the COVID-19 pandemic: Moderator role of disaster stressor and mediator role of negative affect. Applied Psychology: Health and Well-being, 12(4), 1019-1038. https://doi.org/10.1111/aphw. 12226

Publisher's Note Springer Nature remains neutral with regard to jurisdictional claims in published maps and institutional affiliations. 